\title{
Moderate psychological distress as a barrier to breast cancer screening among women
}

\author{
Umar Yusuf Kabir*1, Angela Askew ${ }^{1}$, Yu Jiang $^{1}$, Soumitra S. Bhuyan², Emmanuel Ezekekwu ${ }^{3}$, Aram Dobalian $^{1}$ \\ ${ }^{1}$ School of Public Health, University of Memphis, Tennessee, United States \\ ${ }^{2}$ School of Planning and Public Policy, Rutgers University, New Jersey, NJ, United States \\ ${ }^{3}$ School of Public Health and Information Sciences, University of Louisville, Louisville, Kentucky, United States
}

Received: June 13, 2020

DOI: $10.5430 /$ jha.v9n4p1
Accepted: July 24, 2020

Online Published: July 31, 2020

\begin{abstract}
Objective: To examine the relationship between Breast Cancer Screening (BCS) and Moderate Psychological Distress (MPD). Also, to assess the effect of aggregating women with No Psychological Distress (NPD) and MPD into one group, as done in prior studies when evaluating the relationship between BCS and Psychological Distress (PD).

Methods: The study population comprised of 34,565 women aged 50-74 years who participated in the National Health Interview Survey from 2013 to 2017. The Kessler-6 PD index score (0-24) was dichotomized (0-12: NPD; > 13: Severe Psychological Distress SPD) and trichotomized (0-5: NPD; 5-12: MPD; > 13 SPD). Two multivariate logistic regressions were conducted for the dichotomous and trichotomous PD categories. Andersen's Behavioral Model of Health Services Use guided the choice of covariates. Data analysis was conducted using SAS version 9.4.

Results: Our study showed $4.6 \%$ had SPD, and 17.9\% had MPD. The latter group (MPD) was included in the NPD group in the dichotomous analysis. In the dichotomous analysis, women with SPD (adjusted Odds Ratio $(\mathrm{aOR})=0.71,95 \% \mathrm{CI}=0.63,0.81, p$ $<.00001)$ were less likely to have received a mammogram than those with NPD. In the trichotomous model, women with SPD $(\mathrm{aOR}=0.76,95 \% \mathrm{CI}=0.67,0.87, p=.0001)$ and $\mathrm{MPD}(\mathrm{aOR}=0.84,95 \% \mathrm{CI}=0.78,0.91, p<.00001)$ were both less likely to have had a mammogram than those with NPD.

Conclusions: Prior studies that included individuals with MPD among those with NPD overestimated the effect of SPD on mammography and minimized the importance of targeting women with MPD along with those that have SPD to enhance the uptake of mammography.
\end{abstract}

Key Words: Mental illness, Psychological distress, Breast cancer screening, Mammogram, Mental health

\section{INTRODUCTION}

Breast cancer is the most common cancer for women in the United States, with approximately 3.5 million women living with breast cancer in this country. ${ }^{[1]}$ In 2020 , this malignancy is estimated to affect more than 276,000 new patients and will result in the death of approximately 42,000 individuals. ${ }^{[2]}$ Breast cancer is also associated with a con- siderable economic burden. ${ }^{[2]}$ More than $\$ 180$ billion is lost annually from the treatment of breast cancer and losses in productivity. ${ }^{[3]}$

The survival rate for breast cancer has significantly improved over time as a result of early detection and advances in treatment. ${ }^{[3]}$ Since recommendations for breast cancer screening were introduced in the late 80 s, the rate of breast canStates.

*Correspondence: Umar Yusuf Kabir; Email: uykabir@memphis.edu; Address: 136b Robison, 3720 Alumni Ave, Memphis, TN 38152, United 
cer screening has dramatically increased. ${ }^{[4,5]}$ Mammogram, which is considered to be the cornerstone for detecting breast cancer in its early stages, has been shown to have a significant impact on women's health outcomes. For example, several studies found that mammogram is significantly associated with a reduction in breast cancer-related mortality among women. ${ }^{[6]}$ Currently, the United States Preventative Services Task Force (USPSTF) recommends that women between the ages of 50 and 74 receive a biennial mammography screening. ${ }^{[6]}$

Nevertheless, in 2015, the Centers for Disease Control and Prevention (CDC) reported that breast cancer screening rates fell short of the Healthy People 2020 goal. ${ }^{[7]}$ Moreover, there are reports of disparities in screening rates among the medically underserved population. ${ }^{[8]}$ In particular, disparities in screening related to mental illness remain among the least studied among the disparities. ${ }^{[9]}$

Results from the studies that have examined cancer screening in women with psychological distress have been mixed. While some studies found individuals with PD to have lower odds of breast cancer screening, ${ }^{[10-12]}$ other studies found no significant association ${ }^{[13]}$ or a positive association. ${ }^{[14,15]}$ However, most extant studies had small sample sizes or selection biases. ${ }^{[11]}$

Psychological distress is a state of emotional suffering characterized by the symptoms of depression and anxiety. ${ }^{[16]}$ Accordingly, the Kessler-6, a scale that measures PD developed in 2002, is increasingly and widely being used in measuring psychological symptoms in individuals. The scale is brief and has high accuracy in distinguishing between probable DSM-IV cases and non-cases. ${ }^{[17,18]}$ These features made the scale an ideal screening tool for identifying individuals with severe mental illness in population-based health surveys. ${ }^{[19]}$ The Kessler- 6 scale traditionally categorizes individuals into those with Severe Psychological Distress (SPD) and those with No Psychological Distress (NPD) based on their score on a 6-item questionnaire. ${ }^{[17]}$ In 2012, research suggested recategorization of the scale to include Moderate Psychological Distress (MPD) as a distinct group. ${ }^{[19]}$ The suggestion is based on the evidence that people with MPD have mental health services needs, impairments, substance use, and other risks that are dissimilar to those with the NPD. Therefore, individuals with MPD are an essential target for interventions to reduce health and healthcare disparities.

Existing studies about breast cancer screening in women have only used the dichotomous classification of PD as measured by the Kessler- 6 scale. ${ }^{[1]}$ Thus, the relationship, if any, between breast cancer screening among women and MPD, is unknown. Also, the Kessler-6 scale is increasingly being adopted and ubiquitously employed to identify individuals with PD in research and policymaking. This extensive usage of the scale makes it important to examine the impact of trichotomizing this scale instead of dichotomizing it. To address these two concerns, this study examines the relationship between MPD and mammogram using Kessler-6-scale. It also assesses the effect of aggregating women with NPD and those with MPD into one group when evaluating the relationship between breast cancer screening and PD.

\section{METHODS}

\subsection{Data source}

This study used the National Health Interview Survey (NHIS) data from 2013-2017 extracted using IPUMS database. ${ }^{[20]}$ The NHIS is an annual, in-person household interview conducted by the National Center for Health Statistics of the CDC and covers a wide variety of health topics. Since 1957, this survey has continually collected data from a nationally representative sample of 35,000-40,000 households $(75,000$ 100,000 persons). ${ }^{[21]}$

The NHIS uses a complex, multistage probability sampling technique. A Primary Sampling Unit (PSU) is first identified, which corresponds to a county or a group of small adjacent counties, and then a cluster of households or dormitories within the PSU is further selected. An adult is selected from each selected house within a cluster to form the Sample Adult Questionnaire subsample.

\subsection{Study sample}

The original unweighted size of the 2013-2017 NHIS survey was 495,663 respondents. Using data from the Sample Adult Questionnaire, we included women that are between the ages of fifty to seventy-four that answered the Kessler- 6 and also responded to the breast cancer screening question, resulting in the final study sample size of 34,565 .

\subsection{Measures}

\subsubsection{Mammogram screening}

Our outcome of interest is receipt of a mammogram. The relevant question from the NHIS is "Have you had a mammogram during the past 12 months?" The response is dichotomized as Yes/No.

\subsubsection{Psychological distress}

Psychological distress was measured using the Kessler-6, a well-validated scale for measuring psychological distress, with high accuracy in discriminating the Diagnostic and Statistical Manual of Mental Disorders, 4th Edition (DSM-IV) cases from non-cases for various sociodemographic subsamples. $^{[22]}$ 
This scale asks respondents how often they experience feelings of worthlessness, nervous, hopeless, restless, effort, and depression within the past 30 days. The questions use a 5-point Likert scale ranging from zero (None of the time) to four (All of the time) for all responses. The score from each question is summed to form a Kessler- 6 index that ranges from 0-24. Individuals that score lower than 13 are referred to as NPD and individuals that score 13 and above are considered to have SPD in the traditional dichotomous classification of PD. However, in the new trichotomous categorization of PD, individuals that score less than five are considered to have NPD. If an individual scored 5 to 12 or 13 to 24, the person is considered to have MPD or SPD, respectively. ${ }^{[19]}$ These variables were used as our primary independent variable in the two models.

\subsubsection{Covariates}

The covariates for this analysis were selected using the three constructs of the Andersen model, which uses a combination of predisposing, enabling, and needs factors to predict or explain health services utilization. ${ }^{[23]}$ The predisposing variables in this study include Race (White, Black, Asian or Other), Education status (Less than high school, High school/GED, or Some college and above), and Marital status (Unmarried, Divorced or Married). Enabling factors include Employment status (Unemployed/Employed), Poverty level (Above/Below) Usual Source of care (Yes/No), Health Insurance status (Yes/No), and Region of the country (Northeast, North, Central/Midwest South or West). Included needs factors were Smoking status (Never, Former, Current), Health status (Bad to fair, or Good to Excellent), and History of cancer (Yes/No) and Functional Limitation (Yes/No).

\subsection{Statistical analysis}

For this study, we used the individual as the unit of analysis. We summarized the categorical variables using counts and percentages. Chi-square tests were used to test for the association between receipt of a mammogram and the various independent variables.

We also performed a logistic regression to assess the association between receipt of mammogram and PD while controlling for confounding. Confounding was assessed using the backward elimination approach by applying the $10 \%$ rule. Two different models, one for dichotomized PD and the other for a trichotomized PD, were used. The analysis was conducted using SAS version 9.4 and significance was set at 0.05 , and a non-overlapping $95 \%$ confidence interval. In addition, multiple testing and comparison were adjusted using the Bonferroni correction. To achieve an appropriate estimation of variance, survey procedures PROC SURVEYFREQ and PROC SURVEYLOGISTIC from SAS were used to adjust for the complex survey design. ${ }^{[24]}$

\section{RESUlts}

Table 1 shows the study population characteristics by receipt of mammograms. The total study sample for this study is 34,565 , which corresponds to a weighted size of $224,631,884$ women. Approximately Sixty-two percent of the respondents received a mammogram within the past 12 months. In the dichotomous classification of PD, the majority of the sample had NPD (95.4\%). When PD was categorized into three levels, the majority of the population still had NPD (77.6\%). Like in the dichotomous categorization of PD, the severely distressed individual also accounted for $4.6 \%$ of the sample in the trichotomous categorization of PD. A majority of the sample was White (80.9\%) followed by Black (11.8\%), while Asians and Native Americans accounted for a small fraction of the sample size $(5.1 \%$ and $0.8 \%$, respectively). More than half of the sample were married (59.5\%), had some college education $(62 \%)$, and were unemployed $(50.1 \%)$. Very few of the respondents had no health insurance (6.8\%), no usual source of care (5.4\%), cancer $(15 \%)$, or bad/fair health (18.1\%). Most of the respondents never smoked (59.7\%), are above the federal poverty line (89.8\%), have a functional limitation (54.1\%), and the largest proportion resides in the South (37.6\%).

Table 2 shows the relationship between breast cancer screening and the independent variables. Breast cancer screening was significantly associated with all the independent variables except for the poverty level.

In the trichotomous classification of $\mathrm{PD}$, there were more respondents that had NPD and received a mammogram within the past 12-months $(49.3 \%)$ compared to those that have NPD but did not receive a mammogram (28.2\%). This relationship was also true for those with MPD. There were more women that had MPD and received a mammogram (10\%) than individuals with MPD that did not receive a mammogram (7.9\%). However, there was the same proportion of women with SPD that received a mammogram (2.3\%) compared to those that have SPD but who did not receive a mammogram (2.3\%).

In the analysis with the dichotomous classification of PD, the proportion of women with SPD that received a mammogram $(2.3 \%)$ is also the same as those with SPD who did not receive one (2.3\%). But, those with NPD that received a mammogram was larger (59.3\%) compared to those with NPD but who did not utilize a mammogram within the past 12-months (36.1\%). 
Table 1. Demographics and mammogram use

\begin{tabular}{|c|c|c|c|}
\hline Variable & Freq & Weighted Freq & $(\%)$ \\
\hline \multicolumn{4}{|l|}{ Breast cancer checkup } \\
\hline No & 13,678 & $86,350,461$ & 38.4 \\
\hline Yes & 20,887 & $138,281,423$ & 61.6 \\
\hline \multicolumn{4}{|l|}{ Trichotomous PD } \\
\hline No & 26,404 & $174,223,447$ & 77.6 \\
\hline Moderate & 6,425 & $40,137,226$ & 17.9 \\
\hline Severe & 1,736 & $10,271,211$ & 4.6 \\
\hline \multicolumn{4}{|l|}{ Dichotomous PD } \\
\hline Severe & 1,736 & $10,271,211$ & 4.6 \\
\hline No & 32,829 & $214,360,673$ & 95.4 \\
\hline \multicolumn{4}{|l|}{ Race } \\
\hline White & 27,262 & $181,432,562$ & 80.9 \\
\hline Black & 4,825 & $26,547,832$ & 11.8 \\
\hline Native Americans & 322 & $1,810,744$ & 0.8 \\
\hline Asian & 1,504 & $11,534,511$ & 5.1 \\
\hline Others & 589 & $2,970,914$ & 1.3 \\
\hline \multicolumn{4}{|l|}{ Marriage } \\
\hline Unmarried & 3,705 & $18,704,191$ & 8.3 \\
\hline Divorced & 14,864 & $72,019,503$ & 32.1 \\
\hline Married & 15,878 & $133,304,494$ & 59.5 \\
\hline \multicolumn{4}{|l|}{ Education } \\
\hline Less High School & 4,415 & $26,197,952$ & 11.7 \\
\hline High School/GED & 9,039 & $58,901,575$ & 26.3 \\
\hline Some College > & 20,992 & $138,713,001$ & 62.0 \\
\hline \multicolumn{4}{|l|}{ Employment } \\
\hline Unemployed & 18,367 & $114,479,756$ & 51.0 \\
\hline Employed & 16,191 & $110,115,868$ & 49.0 \\
\hline \multicolumn{4}{|l|}{ USC } \\
\hline No & 1,941 & $12,053,406$ & 5.4 \\
\hline Yes & 32,620 & $212,548,999$ & 94.6 \\
\hline \multicolumn{4}{|l|}{ Region } \\
\hline North East & 6,044 & $42,687,881$ & 19.0 \\
\hline Northcentral/Midwest & 7,341 & $49,419,661$ & 22.0 \\
\hline South & 12,634 & $84,421,604$ & 37.6 \\
\hline West & 8,546 & $48,102,738$ & 21.4 \\
\hline \multicolumn{4}{|l|}{ Smoking status } \\
\hline Never & 19,957 & $133,954,262$ & 59.7 \\
\hline Former & 9,183 & $58,363,748$ & 26.0 \\
\hline Current & 5,379 & $32,034,809$ & 14.3 \\
\hline \multicolumn{4}{|l|}{ Health status } \\
\hline Bad/fair & 6,780 & $40,685,184$ & 18.1 \\
\hline Good/Excellent & 27,774 & $183,883,256$ & 81.9 \\
\hline \multicolumn{4}{|l|}{ Insurance } \\
\hline Yes & 32,142 & $208,692,801$ & 93.2 \\
\hline No & 2,340 & $15,156,995$ & 6.8 \\
\hline \multicolumn{4}{|l|}{ Cancer history } \\
\hline No & 29,292 & $190,811,347$ & 85.0 \\
\hline Yes & 5,241 & $33,570,141$ & 15.0 \\
\hline \multicolumn{4}{|l|}{ Poverty } \\
\hline Below & 4,445 & $21,368,688$ & 10.2 \\
\hline Above & 28,010 & $188,762,026$ & 89.8 \\
\hline \multicolumn{4}{|l|}{ Functional limitation } \\
\hline No & 15,047 & $103,106,211$ & 45.9 \\
\hline Yes & 19,500 & $121,431,470$ & 54.1 \\
\hline
\end{tabular}


Table 2. Relationship between dichotomous psychological distress and trichotomous psychological distress with breast cancer screening

\begin{tabular}{|c|c|c|c|c|c|c|c|}
\hline \multirow{3}{*}{ Variables } & \multicolumn{7}{|c|}{ Breast Cancer Screening } \\
\hline & \multicolumn{3}{|c|}{ No } & \multicolumn{3}{|c|}{ Yes } & \multirow[b]{2}{*}{ sig } \\
\hline & Freq & Weighted Freq & $(\%)$ & Freq & Weighted Freq & $(\%)$ & \\
\hline \multicolumn{8}{|l|}{ Trichotomous PD } \\
\hline Low & 9,852 & $63,000,000$ & 28.2 & 16,552 & $110,000,000$ & 49.3 & \\
\hline Moderate & 2,925 & $18,000,000$ & 7.9 & 3,500 & $22,000,000$ & 10.0 & \\
\hline Severe & 901 & $5,209,473$ & 2.3 & 835 & $5,061,738$ & 2.3 & \\
\hline Dichotomous PD & & & & & & & ** \\
\hline Severe & 901 & $5,209,473$ & 2.3 & 835 & $5,061,738$ & 2.3 & \\
\hline No & 12,777 & $81,140,988$ & 36.1 & 20,052 & $133,219,685$ & 59.3 & \\
\hline \multicolumn{8}{|l|}{ Race } \\
\hline White & 10,874 & $70,000,000$ & 31.3 & 16,388 & $110,000,000$ & 49.6 & \\
\hline Black & 1,779 & $9,377,038$ & 4.2 & 3,046 & $17,000,000$ & 7.7 & \\
\hline Native-Americans & 143 & 833,285 & 0.4 & 179 & 977,459 & 0.4 & \\
\hline Asians & 588 & $4,494,005$ & 2.0 & 916 & $7,040,506$ & 3.1 & \\
\hline Marriage & & & & & & & $* *$ \\
\hline Unmarried & 1,569 & $8,075,928$ & 3.6 & 2,136 & $11,000,000$ & 4.7 & \\
\hline Divorced & 6,474 & $32,000,000$ & 14.1 & 8,390 & $40,000,000$ & 18.1 & \\
\hline Married & 5,579 & $46,000,000$ & 20.7 & 10,299 & $87,000,000$ & 38.8 & \\
\hline Education & & & & & & & ** \\
\hline Less High School & 2,153 & $13,000,000$ & 5.6 & 2,262 & $14,000,000$ & 6.1 & \\
\hline High School-/GED & 3,923 & $25,000,000$ & 11.3 & 5,116 & $34,000,000$ & 15.0 & \\
\hline Some College > & 7,535 & $48,000,000$ & 21.4 & 13,457 & $91,000,000$ & 40.5 & \\
\hline \multicolumn{8}{|l|}{ Employment } \\
\hline Unemployed & 7,433 & $45,000,000$ & 20.1 & 10,934 & $69,000,000$ & 30.9 & \\
\hline Employed & 6,240 & $41,000,000$ & 18.3 & 9,951 & $69,000,000$ & 30.7 & \\
\hline USC & & & & & & & ** \\
\hline No & 1,505 & $9,307,981$ & 4.1 & 436 & $2,745,425$ & 1.2 & \\
\hline Yes & 12,171 & $77,000,000$ & 34.3 & 20,449 & $140,000,000$ & 60.3 & \\
\hline \multicolumn{8}{|l|}{ Region } \\
\hline South & 5,142 & $33,000,000$ & 14.9 & 7,492 & $51,000,000$ & 22.7 & \\
\hline West & 3,498 & $19,000,000$ & 8.2 & 5,048 & $30,000,000$ & 13.2 & \\
\hline Smoking status & & & & & & & $* *$ \\
\hline Never & 7,201 & $47,000,000$ & 21.0 & 12,756 & $87,000,000$ & 38.7 & \\
\hline Former & 3,435 & $21,000,000$ & 9.5 & 5,748 & $37,000,000$ & 16.5 & \\
\hline Current & 3,021 & $18,000,000$ & 8.0 & 2,358 & $14,000,000$ & 6.3 & \\
\hline \multicolumn{8}{|l|}{ Health Status } \\
\hline Bad/fair & 3,261 & $19,000,000$ & 8.6 & 3,519 & $21,000,000$ & 9.5 & \\
\hline Good/Excellent & 10,413 & $67,000,000$ & 29.9 & 17,361 & $120,000,000$ & 52.0 & \\
\hline Insurance & & & & & & & ** \\
\hline Yes & 11,950 & $75,000,000$ & 33.6 & 20,192 & $130,000,000$ & 59.6 & \\
\hline No & 1,683 & $11,000,000$ & 4.8 & 657 & $4,496,522$ & 2.0 & \\
\hline \multicolumn{8}{|l|}{ Cancer history } \\
\hline No & 11,902 & $75,000,000$ & 33.6 & 17,390 & $120,000,000$ & 51.5 & \\
\hline Yes & 1,759 & $11,000,000$ & 4.8 & 3,482 & $23,000,000$ & 10.1 & \\
\hline Functional limitation & & & & & & & $* *$ \\
\hline No & 5,747 & $38,000,000$ & 16.8 & 9,300 & $65,000,000$ & 29.1 & \\
\hline Yes & 7,924 & $48,000,000$ & 21.6 & 11,576 & $73,000,000$ & 32.5 & \\
\hline \multicolumn{8}{|l|}{ Poverty } \\
\hline Below & 2,282 & $11,000,000$ & 5.3 & 2,163 & $10,000,000$ & 4.9 & \\
\hline Above & 10,544 & $70,000,000$ & 33.1 & 17,466 & $120,000,000$ & 56.7 & \\
\hline
\end{tabular}

The proportion of Whites that received a mammogram (49.6\%) within the past 12-months is higher than those who did not receive a mammogram $(31.3 \%)$. That also holds true for Blacks, Asians, and other races with more of each group receiving a mammogram compared to those that did not receive a mammogram among each group. However, there was an equal proportion of women that received a mammogram compared to the proportion that did not among 
Native-Americans $(0.4 \%)$.

There were more women that were screened for breast cancer compared to those that did not get screened among unmarried ( $4.7 \%$ vs. $3.6 \%)$, divorced (18.1\% vs. $14.1 \%)$, and married (38.8\% vs. $20.7 \%)$ women in our study. More participants received a mammogram than those that did not receive one for the various sub-groups of educational level, employment sta- tus, regions, health status, cancer status, functional limitation, and poverty level categories.

However, our result showed that there were more women that did not receive a mammogram compared to those that received a mammogram in women that have no insurance (4.8\% vs. $2 \%)$, no USC $(4.1 \%$ vs. $1.2 \%)$ or are current smokers ( $8 \%$ vs. $6.3 \%)$.

Table 3. Relationship between dichotomous psychological distress and trichotomous psychological distress with breast cancer screening

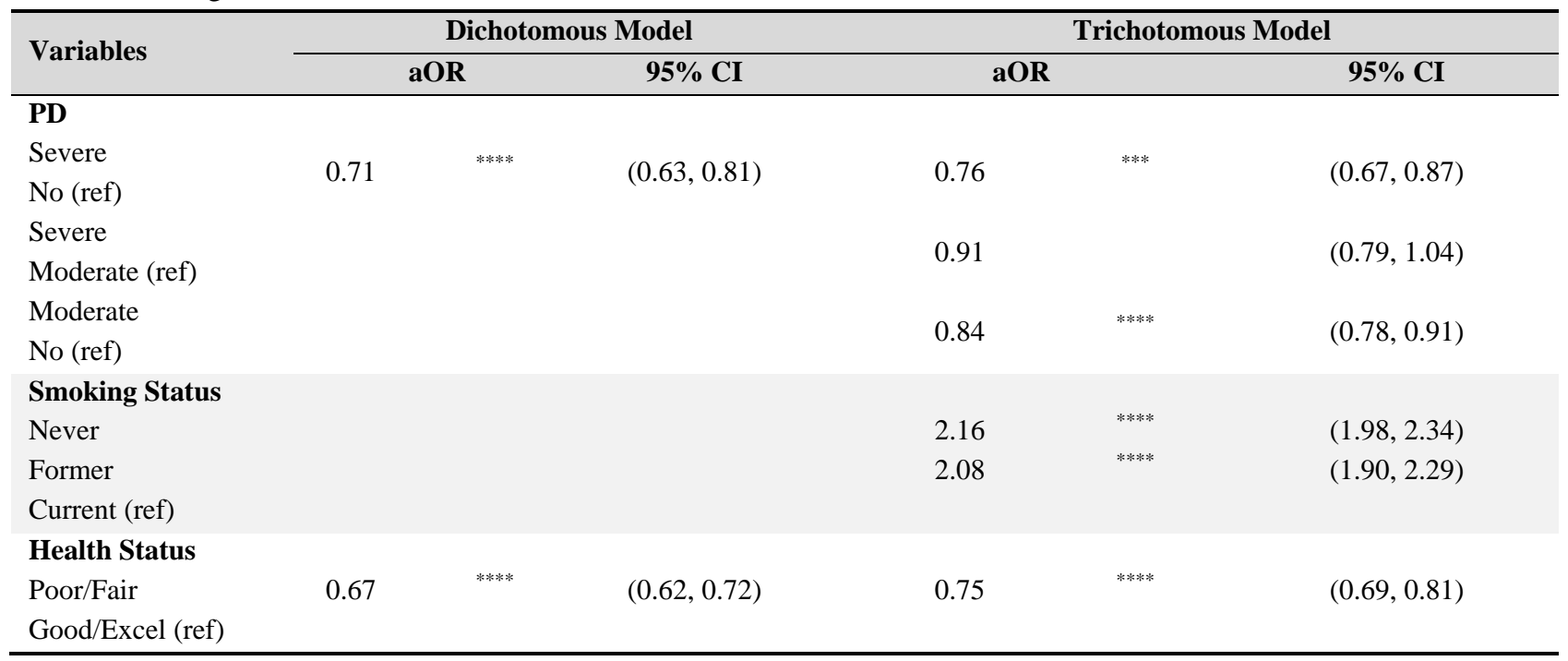

Note. aOR (adjusted Odd Ratio); ${ }^{* * *} p$-value $<.001 ;{ }^{* * * *} p$-value $<.0001 ;$ aOR and $95 \%$ CI are unadjusted for multiple testing/comparison but pvalues are adjusted using Stepdown Bonferroni correction

The results of the logistic regression (see Table 3) indicate that women with SPD were $29 \%$ less likely to receive a mammogram $(\mathrm{aOR}=0.71,95 \% \mathrm{CI}=0.63,0.81, p<.00001)$ compared to those that have NPD in the dichotomized categorization of PD. Compared to individuals with NPD in the trichotomized $\mathrm{PD}$, women with $\mathrm{SPD}(\mathrm{aOR}=0.76,95 \% \mathrm{CI}=$ $0.67,0.87, p=.0001)$ and those with MPD (aOR $=0.84,95 \%$ $\mathrm{CI}=0.78,0.91, p<.00001)$ were $24 \%$ and $16 \%$ less likely to have received a mammogram within the past 12 -months, respectively. The relationship between SPD and MPD that was assessed in the trichotomous model was not statistically significant.

In the dichotomous and trichotomous models, health status was found to be a significant confounder in the relationship between PD and the use of mammograms. Compared to those that perceived their health to be either good/excellent, women with perceived poor/fair were $33 \%$ and $25 \%$ less likely to receive a mammogram in the dichotomous model $(\mathrm{OR}=0.67,95 \% \mathrm{CI}=0.62,0.72, p<.0001)$ and trichotomous model $(\mathrm{OR}=0.75,95 \% \mathrm{CI}=0.69,0.81, p<.0001)$, respectively. Smoking status was also a confounder in the trichotomous model. Compared to those that are current 6 smoker, women that have never smoked were 2.2 times more likely to receive a mammogram $(\mathrm{OR}=2.16,95 \% \mathrm{CI}=1.98$, $2.34, p<.0001)$, and those that were former smokers are 2.1 times more likely to receive a mammogram $(\mathrm{OR}=2.08,95 \%$ $\mathrm{CI}=1.90,2.29, p<.0001)$.

\section{DisCUSSION}

To our knowledge, this is the first study using a national representative sample of women 50-74 years that examined the relationship between receipt of USPSTF recommended mammograms and the three-level categorization of PD (trichotomous) as measured by the Kessler- 6 scale. Traditionally, the relationship between PD and receipt of mammograms has been examined using a two-level categorization of PD (dichotomous). The trichotomous classification of PD made it possible for us to examine the true relationship between the three various levels of PD and the use of mammograms. The prevalence of SPD in both categorizations was $4.6 \%$. This closely reflects the prevalence of SPD for women in the general public, which is $3.9 \% .{ }^{[25]}$ In the trichotomous categorization of PD, MPD had a prevalence of $17.9 \%$, indicating that $17.9 \%$ of the study sample that would 
have otherwise been categorized as having no PD, should be considered to have a milder form of PD. The proportion of women that had a mammogram within the last 12-months in our study sample was $61.6 \%$, which is less than the proportion of women who received a mammogram in the general population $(71.7 \%) .{ }^{[26]}$

In line with prior studies, this study found that women with PD or psychological disorders are less likely to receive preventative services. ${ }^{[11,27]}$ However, our study found that literature that reported a dichotomous measure of PD underestimated the effects of PD on receipt of mammograms. When PD is dichotomized, women with SPD were 29\% less likely to receive a mammogram than women with NPD. However, when PD is trichotomized, SPD women were $24 \%$ less likely to receive a mammogram compared to women with NPD. This is a five percent difference in the likelihood of receipt of a mammogram between the two categorizations. Perhaps the most important finding in this study is the relationship between MPD and the use of mammograms. Women with MPD were found to be $16 \%$ less likely to receive a mammogram compared to those that had no PD. The finding of a significant relationship between MPD and NPD, coupled with the lack of statistically significant difference between SPD and MPD affirms prior studies showing that moderately distressed individuals belong to a distinct category that is different from NPD, and also have a healthcare utilization challenges. ${ }^{[19]}$

By comparing these two models, our research highlights the utility of categorizing PD into three levels to more accurately estimate the effect of SPD on mammogram use. It also calls in question the validity of prior research that dichotomized PD and failed to find statistical significance. And most important, the identification of individuals with MPD, who are larger in proportion within the community compared to those with SPD, as likely having a barrier to receipt of mammograms, will provide policymakers with an additional target for interventions that seek to improve the adoption of mammogram screening. Lastly, our findings highlight the usefulness of the Kessler- 6 tool for screening those at risk of forgoing breast cancer screening.

\subsection{Limitations}

We used cross-sectional data, and so causation cannot be inferred. The data is self-reported, and there is the possibility of recall or social desirability bias among respondents. For example, the bias introduced by answering self-reporting the Kessler-6 scale might have a possible impact on the study's treatment effects. However, it is unclear that these biases might affect the three groups differently. Moreover, for the Kessler-6 scale, it is well-validated and research has found it

Published by Sciedu Press to be consistent in capturing PD levels with minimal discrepancies among different subpopulations. Despite our attempt to controlling for several potential confounders, some residual confounding from unmeasured variables may invariably biased our results. To minimized this bias, we used the Andersen's Behavioral Model of Health Services Use to identify our potential confounders. It should also be noted that both severe and moderate PD are non-specific for a clinical diagnosis of mental illness; ${ }^{[25]}$ instead, the Kessler- 6 scale measures depression and anxiety symptoms.

\section{Conclusions AND IMPlications}

There overwhelming evidence suggesting that early screening of breast cancers using mammogram decreases breast cancer-related mortality. ${ }^{[6,28,29]}$ Conversely, individuals with psychological distress have been shown to carry a disproportionate burden of cancers and cancer-related death. ${ }^{[30,31]}$ This underscores the importance of screening for cancers in individuals that have psychological distress. Nonetheless, our study found that severely and moderately psychologically distressed women fifty to seventy-four years in the United States have lower odds of mammogram use. We also found that prior research that categorized women into those that either has severe or no psychological distress using the Kessler scale might have significantly overestimated the effect of having severe psychological distress on mammogram use. Therefore, we suggest that future research that uses this scale to examine health services use should ensure that moderately psychologically distress individuals are treated as a distinct group. The lower observed utilization of mammograms among women with SPD and MPD also warrants further investigation to determine how best to improve mammogram use for these individuals. To address the general problem of underutilization of preventative services ${ }^{[32,33]}$ and the specific issue of breast cancer screening, ${ }^{[7-9]}$ policymakers and healthcare providers must pay close attention to women with both MPD and SPD. Due to the simplicity of its administration, practitioners can utilize the Kessler-6 scale as a screener to identify women (MPD and SPD) at risk of not adhering to the USPSTF recommendations. Special interventions like reminders and other cues to actions could be used to encourage them to get screened. The Kessler- 6 scale could also be administered to women that have missed a couple of screenings to see if their non-adherence is related to psychological distress so that it could be effectively addressed.

\section{DATA AVAILABILITY STATEMENT}

The datasets analyzed during the current study are available in the IPUMS repository, https://nhis . ipums .org/nhi $\mathrm{s} /$. 


\section{ETHICAL STANDARDS}

We declare that this manuscript complies with the current laws of the United States of America.

\section{CONFLICTS OF INTEREST DisClOSURE}

The authors declare they have no conflicts of interest.

\section{REFERENCES}

[1] National Cancer Institute. Female Breast Cancer: Statistics at a glance. 2019. Available from: https://seer.cancer.gov/stat facts/html/breast.html

[2] National Cancer Institute. Female Breast Cancer: Statistics at a glance. 2020. Available from: https ://seer.cancer.gov/stat facts/html/breast.html

[3] Blumen H, Fitch K, Polkus V. Comparison of Treatment Costs for Breast Cancer, by Tumor Stage and Type of Service. American Health \& Drug Benefits. 2016; 9(1): 23.

[4] Eddy DM. Screening for Breast Cancer. Annals of Internal Medicine. 1989; 111(5): 389-399. PMid: 2504094. https://doi.org/10.7 326/0003-4819-111-5-389

[5] National Committee for Quality Assurance. The State of Health Care Quality. 2014; Available from: http: //store.ncqa.org/index.php/catalog/product/view/id /2341/s/2015-state-of-health-care-quality-report/

[6] Siu AL. Screening for breast cancer: US Preventive Services Task Force recommendation statement. Annals of Internal Medicine. 2016; 164(4): 279-296. PMid: 26757170. https://doi.org/10.7326/ M15-2886

[7] National Cancer Institute. Cancer Screening Rates Missing Targets 2015. Available from: https://www.cancer.gov/news-event s/cancer-currents-blog/2015/screening-targets

[8] Ngo V, Degan M, Ho E, et al. Evaluation of the United States Preventative Services Task Force Screening Guidelines for Breast Cancer in a Hispanic Underserved Population. Cureus. 2020; 12(5). https://doi.org/10.7759/cureus.8030

[9] Aggarwal A, Pandurangi A, Smith W. Disparities in Breast and Cervical Cancer Screening in Women with Mental Illness: A systematic literature review. American Journal of Preventive Medicine. 2013; 44(4): 392-398. PMid: 23498106. https ://doi.org/10.1016/j amepre.2012.12.006

[10] Lerman C, Kash K, Stefanek ME. Younger women at increased risk for breast cancer: perceived risk, psychological well-being, and surveillance behavior. Journal of the National Cancer Institute. Monographs. 1994(16): 171-176.

[11] Xiang X. Serious psychological distress as a barrier to cancer screening among women. Women's Health Issues. 2015; 25(1): 49-55. PMid: 25442364. https ://doi.org/10.1016/j .whi.2014.09. 001

[12] O'Donnell S, Goldstein B, DiMatteo MR, et al. Adherence to mammography and colorectal cancer screening in women 50-80 years of age: the role of psychological distress. Women's Health Issues. 2010; 20(5): 343-349. PMid: 20800770. https ://doi.org/10.1016/j . whi. 2010.04.002

[13] Pirraglia PA, Sanyal P, Singer DE, et al. Depressive symptom burden as a barrier to screening for breast and cervical cancers. Journal of Women's Health. 2004; 13(6): 731-738. PMid: 15333288. https://doi.org/10.1089/jwh.2004.13.731

[14] Green CA, Pope CR. Depressive symptoms, health promotion, and health risk behaviors. American Journal of Health Promotion. 2000;
15(1): 29-34. PMid: 11184116. https ://doi.org/10.4278/08 90-1171-15.1.29

[15] Honda K, Goodwin RD, Neugut AI. The associations between psychological distress and cancer prevention practices. Cancer Detection and Prevention. 2005; 29(1): 25-36. PMid: 15734214 https ://doi.org/10.1016/j.cdp.2004.08.004

[16] Mathew KJ, Pathak A, Rai S, et al. Risk of Psychological Distress Among Individuals Living with a Mentally Ill Person: A Study from a Backward State of India and its Implications. Online J Health Allied Scs. 2016; 15(4): 6

[17] Kessler RC, Andrews G, Colpe LJ, et al. Short screening scales to monitor population prevalences and trends in non-specific psychological distress. Psychological Medicine. 2002; 32(6): 959-976. PMid: 12214795. https://doi.org/10.1017/S0033291702006074

[18] Easton SD, Safadi NS, Wang Y, et al. The Kessler psychological distress scale: translation and validation of an Arabic version. Health and Quality of Life Outcomes. 2017; 15(1): 215. PMid: 29078774. https ://doi .org/10.1186/s12955-017-0783-9

[19] Prochaska JJ, Sung HY, Max W, et al. Validity study of the K6 scale as a measure of moderate mental distress based on mental health treatment need and utilization. International Journal of Methods in Psychiatric Research. 2012; 21(2): 88-97. PMid: 22351472. https://doi.org/10.1002/mpr.1349

[20] Blewett LA, Drew JAR, Griffin R, et al. IPUMS health surveys: National health interview survey, Version 6.4. Minneapolis: University of Minnesota; 2016. D070 p.

[21] Centers for Disease Control and Prevention. National Center for Health Statistics: About the National Health Interview Survey. 2018 Available from: https://www.cdc.gov/nchs/nhis/about_nh is.htm

[22] Kessler RC, Barker PR, Colpe LJ, et al. Screening for Serious Mental Illness in the General Population. Archives of General Psychiatry. 2003; 60(2): 184-89. PMid: 12578436. https://doi.org/10.1 001/archpsyc.60.2.184

[23] Andersen RM. Revisiting the behavioral model and access to medical care: does it matter?. Journal of Health and Social Behavior. 1995; 1-10. PMid: 7738325. https ://doi .org/10.2307/2137284

[24] An AB. Performing Logistic Regression on Survey Data with the New SURVEYLOGISTIC Procedure. In Proceedings of the twenty-

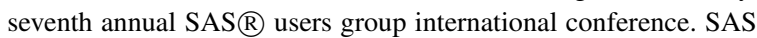
Institute Inc. Cary, NC.; 2002. 258-27 p.

[25] Pratt LA, Dey AN, Cohen AJ. Characteristics of adults with serious psychological distress as measured by the K6 scale, United States. 2007; 2001-04. https : //doi.org/10.1037/e609262007-001

[26] Rosenberg J. Cancer Screening Rates in the US Fall Short of Healthy People 2020 Targets. AJMC. 2018. Available from: https://www.ajmc.com/focus-of-the-week/cancer-scr eening-rates-in-the-us-fall-short-of-healthy-peo ple-2020-targets

[27] Carney CP, Jones LE. The influence of type and severity of mental illness on receipt of screening mammography. Journal of General Internal Medicine. 2006; 21(10): 1097-1104. 29. PMid: 16970559. https://doi.org/10.1111/j.1525-1497.2006.00565.x 
[28] Additional refrence: Feig, S. A. Screening mammography benefit controversies: sorting the evidence. Radiologic Clinics. 2014; 52(3): 455-480. PMid: 24792649. https://doi.org/10.1016/j.rcl. 2014.02.009

[29] Løberg M, Lousdal ML, Bretthauer M, et al. Benefits and harms of mammography screening. Breast Cancer Research. 2015; 17(1): 63. https://doi.org/10.1186/s13058-015-0525-z PMid:25928287 PMCid:PMC4415291

[30] Hamer M, Chida Y, Molloy GJ. Psychological distress and cancer mortality. Journal of Psychosomatic Research. 2009; 66(3): 255258. PMid: 19232239. https://doi.org/10.1016/j.jpsych ores.2008.11.002
[31] Chida Y, Hamer M, Wardle J, et al. Do stress-related psychosocial factors contribute to cancer incidence and survival?. Nature clinical practice Oncology. 2008; 5(8): 466-475. PMid: 18493231. https://doi.org/10.1038/ncponc1134

[32] Mahmood A, Kim H, Kabir U, et al. Food Insecurity and Influenza and Pneumonia Vaccines Uptake Among Community-Dwelling Older Adults in the United States. Journal of Community Health. 2002; 1-11.

[33] Levine S, Malone E, Lekiachvili A, et al. Health care industry insights: why the use of preventive services is still low. Preventing Chronic Disease. 2019. PMid: 30873937. https://doi.org/10 $.5888 /$ pcd16. 180625 